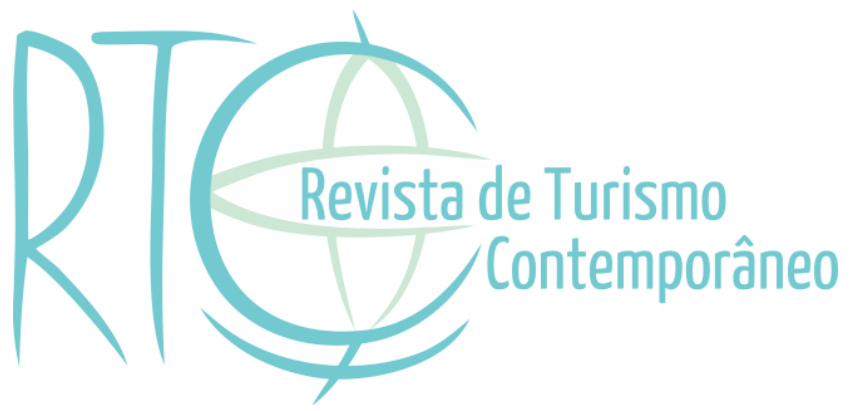

\title{
Criação, formatação, gestão e promoção de bens e experiências turístico-culturais
}

\section{Creation, formatting, management and promotion of tourist-cultural goods and experiences}

Andre Fontan Kohler

Professor da Escola de Artes, Ciências e Humanidades, vinculado ao Curso de Bacharelado em Lazer e Turismo da Universidade de São Paulo - USP, São Paulo/SP, Brasil

E-mail: afontan@usp.br

Artigo recebido em: 13-10-2019

Artigo aprovado em: 19-05-2020 


\section{RESUMO}

Desde pelo menos os anos 1980, tem havido um crescimento expressivo do número de atrações turístico-culturais, dentre as quais atrações principais, centros de interpretação patrimonial e trilhas e roteiros patrimoniais, na Europa Ocidental, América do Norte e Sudeste Asiático. Objetiva-se apresentar, discutir e exemplificar diversas maneiras de criar, formatar, gerir e promover atrações turístico-culturais, isoladamente ou em conjunto, de modo a tornar a oferta turístico-cultural de uma cidade, região ou país mais atrativa para determinados públicos-alvo. O presente artigo aborda o seguinte: a) a criação de uma nova e original atração turístico-cultural; b) o pacote de atrações e outros elementos turísticos e de lazer; c) o desenvolvimento de trilhas e roteiros patrimoniais; d) eventos - destinos turísticos; e) centro de interpretação patrimonial; e f) eventos - atração turístico-cultural. A metodologia de pesquisa consiste, basicamente, em revisão de literatura analítica e de estudos de caso, secundada pela vivência técnico-acadêmica do autor. Enquanto no exterior há o fenômeno do encerramento de atrações turístico-culturais, em virtude de um crescimento acelerado superior ao da demanda, tem ocorrido no Brasil, por parte do poder público e da iniciativa privada, um desinteresse em abrir centros de interpretação patrimonial e desenvolver trilhas e roteiros patrimoniais, dentre outras atrações, mesmo em nossas principais cidades patrimoniais. A "importação" de novos modelos e tipos de atrações turístico-culturais seria algo inovador para o mercado de turismo cultural no Brasil, mesmo que alguns desses já estejam sendo implantados no exterior, nas últimas décadas.

Palavras-chave: Model Culture. Reprodução Autêntica. Trilhas e Roteiros Patrimoniais. Evento. Centro de Interpretação Patrimonial.

\section{ABSTRACT}

Since at least the 1980s, there has been a significant growth of tourist-cultural attractions, including flagship attractions, heritage centers and heritage trails and routes, in Western Europe, North America and Southeast Asia. We aim to present, discuss and exemplify ways to create, format, manage and promote tourist-cultural attractions, by itself or together with others, in order to make the tourist-cultural offer of a city, region or country more attractive to specific market segments. We address the following topics: a) the creation of a new and original tourist-cultural attraction; b) the bundling of attractions and other elements of tourism and leisure; c) the development of heritage trails and routes; d) events - tourist destinations; e) heritage centers; and f) events - tourist-cultural attractions. The research methodology consists of a review of analytical literature and case studies, supported by the author's technical and academic experience. While in other countries some tourist-cultural attractions are closing, the result of growth in the number of attractions above of the tourist demand, there has been in Brazil - by the public sector and the private sector - a lack of interest to develop heritage centers and heritage trails and routes, among other attractions, even in our most important heritage cities. The "import" of new models and types of tourist-cultural attractions would be innovative to cultural tourism in Brazil, even some of these are being developed in other countries in the last decades.

Keywords: Model Culture. Authentic Reproduction. Heritage Trails and Routes. Event. Heritage Center. 


\section{INTRODUÇÃO}

Na Europa Ocidental, América do Norte e Sudeste Asiático, avalia-se que tem havido, nas últimas décadas, um crescimento expressivo do número de atrações turístico-culturais novos museus, centros culturais e centros de interpretação patrimonial, principalmente -, a ponto de a demanda não ter acompanhado esse crescimento (Urry, 2002; Apostolakis, 2003; Richards, 1996). Urry (2002, p. 99, tradução nossa), com a pilhéria inglesa que lhe é habitual, sintetiza duas opiniões acerca desse crescimento visto como excessivo:

\footnotetext{
Um comentarista sugeriu que o Reino Unido brevemente "designará um curador, ao invés de um primeiro-ministro" (citado em Lowenthal, 1985: 4). De modo similar, Tom Wolfe recentemente propôs que o conjunto da população britânica faça parte de uma Disneylândia nacional, em proveito dos turistas estrangeiros ${ }^{1}$.
}

A demanda de turismo cultural tem apresentado crescimento, nas últimas décadas; o ponto é que ele tem sido mais baixo do que o da oferta de turismo cultural. Além disso, os turistas não se distribuem uniformemente entre os destinos; é possível encontrar desde atrações turístico-culturais que, constantemente, apresentam longas filas para a entrada, como a Westminster Abbey, em Londres, até as que não conseguem sustentar-se financeiramente. Uma das consequências desse crescimento acelerado da oferta tem sido o encerramento de atrações ou mesmo de projetos inteiros, pouco tempo após sua inauguração.

Moore (2014) lista centros de interpretação patrimonial e museus britânicos que custaram dezenas de milhões de libras esterlinas, abertos nos últimos 20 anos, e que fecharam as portas após poucos meses de operação. Em 2013, visitou-se o já abandonado Earth Centre, em Doncaster, que consumiu cerca de R 210 milhões $^{2}$, e que declarou falência após cinco anos de funcionamento (1999-2004). Em Sheffield, foi visitado o prédio do National Centre for Popular Music, que custou cerca de R 75 milhões - em grande parte, provenientes da loteria nacional. Aberto em 01 de março de 1999, ele fechou as portas em junho de 2000, devido ao fato de o público sequer ser suficiente para cobrir seus custos operacionais. Atualmente, o prédio abriga o diretório acadêmico da Sheffield Hallam University.

Silberberg (1995) aponta que, no caso de bens e instituições culturais, a formatação (packaging), o marketing e a formação de parcerias não devem apenas fazer com que eles

\footnotetext{
${ }^{1}$ One commentator has suggested that Britain will 'soon be appointing a Curator instead of a Prime Minister' (quoted in Lowenthal, 1985: 4). Similarly, Tom Wolfe has recently proposed that the entire British population service a national Disneyland for foreign tourists.

${ }^{2}$ No presente artigo, considera-se que $£ 1.00$ vale $\mathrm{R} \$ 5,0124$. Utilizou-se a taxa de câmbio libra esterlina-real do Banco Central do Brasil, para 07 de outubro de 2019. Recuperado de http://www4.bcb.gov.br/pec/taxas/port/ptaxnpesq.asp?id=txcotacao. No restante do artigo, colocam-se apenas os valores em reais, já convertidos da libra esterlina.
} 
sejam mais bem avaliados e consumidos por residentes locais, turistas e visitantes com grande interesse em cultura e patrimônio, mas também os tornar atrativos e interessantes para o público com pouco interesse nessas questões. Isso inclui residentes locais, turistas e visitantes para os quais o consumo de atrações turístico-culturais dê-se de forma acidental; por exemplo, por elas localizarem-se perto de seu hotel, ou pelo fato de a pessoa estar acompanhando um grupo de familiares e/ou amigos, não tendo sido a visita à atração em questão uma escolha sua.

A utilização de elementos como os festivais, assim como a defesa dos tão criticados passeios de receptivo e pacotes de viagem, é vista por McKercher e Cros (2002) como uma forma positiva de bolha ambiental (environmental bubble). Eles enfatizam a necessidade de o que definem como redução da estranheza (strangeness reduction) do patrimônio cultural, para o tornar mais acessível aos visitantes e turistas, ao mesmo tempo em que se cria uma ligação com seu quadro de referências ${ }^{3}$.

O presente artigo objetiva apresentar, discutir e exemplificar diversas maneiras de criar, formatar, gerir e promover atrações turístico-culturais, isoladamente ou em conjunto, de modo a tornar a oferta turístico-cultural de uma cidade, região ou país mais atrativa para determinados públicos-alvo.

Justifica-se o presente artigo pela carência de textos, em língua portuguesa, que reúnam as várias maneiras de adensar e de aumentar o potencial turístico de um destino. Köhler (2011) aponta que grande parte das firmas turísticas é, de modo geral, mais conservadora do que até mesmo o turista de massa que viaja por meio de um pacote, no que concerne à disposição a ofertar novos produtos turísticos, principalmente quando se trata de algo novo, ainda sem similar no mercado. Cumpre ressaltar, dessa forma, o papel ativo que o poder público precisa ter, no destino, tanto para o desenvolvimento do turismo cultural - para além das atrações e roteiros mais conhecidos - quanto para a regulação e controle do fluxo, a fim de minorar seus impactos negativos.

A metodologia de pesquisa consiste, basicamente, em revisão de literatura analítica e de estudos de caso, secundada pela vivência técnico-acadêmica do autor. Todos os casos e exemplos provenientes do Brasil, do Reino Unido e da Argentina foram estudados e

\footnotetext{
${ }^{3}$ Desde os anos 1960, o conceito de bolha ambiental tem sido utilizado para descrever o turismo, principalmente o turismo internacional de massa. Contudo, textos seminais como Boorstin (1992) e Turner e Ash (1976) têm uma visão marcadamente pessimista acerca da bolha ambiental, avaliada como uma construção de firmas turísticas, cujo principal resultado é isolar o turista da realidade local. Para uma discussão acerca da relação estabelecida entre a criação de bolhas ambientais e a autenticidade em turismo, conforme tratada por textos seminais publicados nos anos 1960 e 1970, ver Köhler (2009).
} 
pessoalmente visitados; no caso dos dois primeiros países, ambos foram objeto da tese de doutorado e de pesquisas subsequentes do autor. A maior parte dos casos e exemplos trazidos pelo presente artigo provém do Reino Unido; isso se justifica pela importância e magnitude do turismo cultural nesse país, como bem demonstram Urry (2002) e Hewison (1987).

Os demais casos e exemplos sustentam-se apenas por meio de revisão de literatura; para sua seleção, privilegiaram-se trabalhos que trazem bons estudos de caso que contemplem a criação, formatação, gestão e/ou promoção de bens e experiências turístico-culturais.

Em resumo, o adensamento da oferta turística de Auvers-sur-Oise, pequena vila na França, é útil para introduzir os itens do presente capítulo:

Auvers-sur-Oise promove-se vigorosamente como um lugar artístico, e é sobretudo Van Gogh quem constitui o ponto focal dessa atividade. Há uma trilha designada através da vila, pôsteres que reproduzem as pinturas de Van Gogh, expostos perto das vistas que elas retratam, uma exposição no Auberge Ravoux, onde ele morou e morreu; tanto o artista quanto seu irmão Theo estão enterrados no cemitério da vila. Essa imagem de Auvers como a "vila dos artistas" e o "berço do impressionismo" é fortemente promovida pelo Office de Tourisme, com a ajuda de grupos voluntários. As principais inovações recentes foram a reconstrução do Auberge Ravoux, como uma exposição sobre Van Gogh, e o desenvolvimento da apresentação temática "Voyage au temps des impressionists," no Chateau d'Auvers. (Herbert, 1996, p. 83, tradução nossa ${ }^{4}$ ).

\section{A CRIAÇÃO DE UMA NOVA E ORIGINAL ATRAÇÃO TURÍ́TIICO-CULTURAL}

A criação de uma atração turístico-cultural completamente nova é uma das maneiras mais populares de uma cidade ou região tentar aumentar sua atratividade turística. Não por acaso, é uma alternativa particularmente popular entre cidades que, apesar de terem potencial turístico, enfrentam um longo processo de decadência econômica e estigmatização social, ou não conseguem competir com destinos turísticos próximos e/ou com oferta turística similar, como mostram Hatherley $(2010,2012)$ para o Reino Unido e Dodd e Hemel (1999) para a Europa Ocidental.

Em muitos casos, a nova atração é instalada em um prédio de arquitetura icônica, assinado por um integrante do star system mundial ${ }^{5}$. Desse modo, a estrutura arquitetônica

\footnotetext{
${ }^{4}$ Auvers-sur-Oise promotes itself vigorously as an artistic place and it is above all Van Gogh who forms the focal point of this activity. There is a designated trail through the village, poster prints of Van Gogh paintings set against the views which he depicted, an exhibition at the Auberge Ravoux, where Van Gogh lodged and died, and both the artist and his brother Theo are buried in the village cemetery. This image of Auvers as the 'village of artists' and the 'cradle of impressionism' is promoted strongly by the Office de Tourisme with help from voluntary groups. Major recent innovations have been the reconstruction of the Auberge Ravoux as a Van Gogh exhibition and the development of a theme presentation 'Voyage au temps des impressionists' at the Chateau d'Auvors.

${ }^{5} \mathrm{O}$ termo "star system mundial" é utilizado para designar um conjunto de arquitetos de reconhecimento internacional, que, por meio de traços característicos em seus projetos e de sua fama e reconhecida competência, Revista de Turismo Contemporâneo, Natal, v. 8, n. 2, p. 251-273, jul./dez. 2020. 
transforma-se em uma das marcas da cidade, sendo facilmente reconhecida por turistas e visitantes, e servindo de ateste de regeneração urbana, renascimento econômico e atratividade turística da cidade ou região em questão.

A criação de grandes museus e centros culturais ainda é uma opção muito popular. Em Bilbao (Espanha), a abertura de uma filial do Museu Guggenheim, em uma edificação que o passar das décadas (ainda) não conseguiu retirar seu caráter singular e extraordinário, tornou a cidade mundialmente conhecida, ajudando-a a superar (parcialmente) a imagem de centro industrial sujo, decadente e deprimente. Plaza (2000) mostra como a abertura do Museu Guggenheim, por si só, aumentou consideravelmente o número de pernoites na cidade.

Nos anos 2000, vários municípios brasileiros concorreram para receber a filial que o Museu Guggenheim instalaria no país - por exemplo, ela seria uma das âncoras culturais do Complexo Turístico-Cultural Recife Olinda. Apesar de demandar um volume expressivo de recursos públicos, Köhler (2011) mostra que a prefeitura municipal via na atração do Museu Guggenheim a oportunidade de o Recife receber turistas com interesse particular em arte contemporânea.

Já Niterói, sempre eclipsada pelo Rio de Janeiro, mais importante destino de turismo de lazer do Brasil, buscou atrair turistas por meio da construção de novos prédios públicos e equipamentos culturais assinados pelo mais conhecido e reconhecido arquiteto brasileiro, Oscar Niemeyer. Ao aproveitar obras já existentes e novos prédios monumentais assinados pelo arquiteto, o Caminho Niemeyer pretende, quando todos os projetos estiverem concluídos, tornar-se o segundo mais extenso conjunto arquitetônico de autoria de Oscar Niemeyer no Mundo, após Brasília.

Individualmente, destaca-se o Museu de Arte Contemporânea de Niterói, considerado um dos principais projetos da fase madura do arquiteto. Ícone-mor de Niterói, o museu é considerado uma atração turístico-cultural "imperdível”, mesmo para turistas hospedados no Rio de Janeiro, que, ao lá chegar, têm acesso a um dos mais interessantes mirantes para o Rio de Janeiro e Niterói. Isso faz com que, em muitos casos, as exposições de arte não sejam nem sequer vistas, conforme relatos de ex-dirigentes e de funcionários da instituição.

A construção de novos museus e centros culturais é muito utilizada para regenerar núcleos antigos e áreas portuárias abandonadas e deterioradas, a exemplo de o que ocorreu em alguns recintos urbano-turísticos do centro de Manchester (Inglaterra). No antigo porto fluvial 
de Manchester - que, apesar do nome, localiza-se no município vizinho (Salford) -, o projeto de regeneração urbana de a que já foi considerada a área menos promissora do Reino Unido (Urry, 2002; Hatherley, 2010) baseou-se na construção de dois novos equipamentos culturais, ambos assinados por membros do star city mundial e de arquitetura icônica.

O Lowry é um centro cultural que combina teatros com galerias de arte, cuja construção foi beneficiada pelos recursos da loteria nacional, instituída nos anos 1990; por meio dela, dezenas de grandes projetos culturais foram inaugurados no Reino Unido, desde a Tate Modern, em Londres, considerada o caso mais bem-sucedido, até fracassos retumbantes, a exemplo do Earth Centre e do National Centre for Popular Music, vistos anteriormente. O equipamento cultural celebra a obra de Laurence Stephen Lowry, pintor muito apreciado no Nordeste da Inglaterra, onde ficam Manchester e Salford, e colocou a Grande Manchester na rota das grandes exposições de arte contemporânea do Reino Unido.

Já o Imperial War Museum North é uma filial da já centenária matriz inglesa, e resulta da política de os grandes museus nacionais abrirem filiais e/ou emprestarem parte de seu acervo para instituições regionais, inclusive para aumentar a atratividade turística de cidades e regiões pouco visitadas. Dada a vasta reserva técnica dessas instituições, a transferência de parte do acervo não afeta a qualidade nem sequer a variedade de o que é exposto na matriz.

Outro tipo de equipamento cultural muito encontrado em destinos turísticos importantes, principalmente na Ásia e na Oceania, mas ainda inexistente no Brasil - pelo menos, em escala relevante -, é a model culture. Trata-se de uma espécie de parque temático com tema e atavios étnicos, que explora a cultura de uma etnia, minoria ou nacionalidade, dentro de uma clara proposta de lazer e turismo.

Apesar de ter como objeto, no mais das vezes, elementos tradicionais de uma determinada cultura - dança, música, artefatos, culinária etc. -, as model cultures recorrem, muitas vezes, à tecnologia e ao espetáculo, de modo a tornar a experiência mais atrativa e facilmente consumível pelo turista. A descrição das principais atrações do Tjapukai Aboriginal Cultural Park, na Austrália, ilustra bem isso, já nos anos 1990:

\footnotetext{
As três principais atrações são o Teatro da Criação, que combina apresentações ao vivo e tecnologia laser para apresentar uma perspectiva aborígene sobre a criação dos seres humanos; o Teatro da História, que apresenta um filme acerca da história dos aborígenes, desde a chegada dos europeus; e o Teatro da Dança, no qual se apresenta uma mistura de danças aborígenes com informações sobre sua cultura e música contemporânea. (Moscardo \& Pearce, 1999, p. 421, tradução nossa ${ }^{6}$ )
}

\footnotetext{
${ }^{6}$ The three main attractions are the Creation theater which combines live performances and laser technology to present an Aboriginal perspective on the creation of humans; the History theater which runs a film of Aboriginal Revista de Turismo Contemporâneo, Natal, v. 8, n. 2, p. 251-273, jul./dez. 2020. 
Além disso, o Tjapukai Aboriginal Cultural Park permite que o visitante arremesse lanças e bumerangues, prove a culinária local, e toque um instrumento musical tradicional dos aborígenes - o didgeridoo.

Provavelmente, a mais famosa e bem-sucedida model culture, do ponto de vista comercial e financeiro, é o Polynesian Cultural Center (PCC), no Havaí (Estados Unidos da América), estruturada como parque temático que retrata a "cultura tradicional" de sete povos da Polinésia (Havaí, Samoa, Nova Zelândia [aborígene], Fiji, Taiti, Tonga e Ilhas Marquesas). A atração é de propriedade da Igreja de Jesus Cristo dos Santos dos Últimos Dias.

A maior parte dos visitantes costuma passar grande parte do dia na atração. Após um passeio organizado pelo parque - a pé, de canoa ou de bonde -, o visitante fica livre para voltar às várias exibições, que vão desde danças havaianas até artesanato de outros povos. À noite, há o jantar com a culinária típica dos povos da Polinésia, após o qual o turista retornará a seu hotel, em Waikiki, por meio de um ônibus de excursão. O foco do parque temático é nos artefatos culturais, nas habitações e canoas tradicionais e na música e dança da Polinésia, por mais que, atualmente, esses elementos sejam dificilmente encontrados nesses lugares, como o turista mais atento terá facilmente percebido, no caminho de seu hotel para o PCC.

A apresentação da cultura polinésia no PCC segue três pontos principais, a saber:

a) os turistas buscam uma experiência extraordinária e exótica, diferente de seu dia-a-dia;

b) os turistas não têm tempo para uma experiência mais completa, nem sequer conseguem compreender a complexidade da cultura polinésia. Trata-se de turistas hospedados em Waikiki, que vêm para o Havaí com outras motivações, principalmente o composto sexo, sol, mar e praia;

c) o PCC busca oferecer uma experiência divertida e agradável para os turistas, e não discutir a estrutura socioeconômica presente na Polinésia ou elementos culturais mais profundos, como ideologias, formas de organização social e a teia de significados de cada uma das culturas retratadas (Stanton, 1989).

Stanton (1989) - que, de modo geral, defende as model cultures - admite que o quê é representado aos turistas é uma falsa cultura, que não existe mais na Polinésia contemporânea. O centro apresenta elementos culturais em extinção nas ilhas, submetidas a um forte processo Aboriginal dancing with information on their culture and contemporary music. 
de modernização e aculturação nos últimos séculos. Os dois principais problemas apontados por Stanton (1989), em relação ao que é apresentado no PCC, são os seguintes:

a) problema temporal: não fica claro qual é a época retratada pelo PCC. Os artefatos e as apresentações culturais retratam a "cultura tradicional" da Polinésia, mas objetos separados por centenas de anos na história podem estar reunidos em um mesmo cenário ou apresentação;

b) essa "cultura tradicional" é retratada por meio de artefatos culturais, como casas, totens, roupas e elementos de decoração, e artes performáticas, como música, dança e outras apresentações culturais. Como Abram (1996) coloca, tendo em vista outras model cultures, trata-se de uma história e de uma cultura "artefatuais", que não consideram o contexto social e econômico no qual elas desenvolveram-se.

Outra maneira de criar uma atração é a assim chamada "reprodução autêntica" (authentic reproduction). Trata-se de aproveitar remanescentes de algo importante historicamente, seja por sua ligação à figura histórica, acontecimento memorável e/ou ciclo econômico passado, e reconstruir e/ou reconstituir as partes faltantes, de modo a dar uma visão completa de o que se imagina ou se sabe que existiu em determinado período passado.

Por exemplo, a New Salem Historic Site é uma vila reconstruída e museu a céu aberto, onde Abraham Lincoln viveu durante os anos 1830. Nela, o visitante tem uma visão completa de o que teria sido New Salem, no supracitado período, quando Abraham Lincoln lá morou. Em cada uma das casas, há um intérprete que dá uma visão de como a vida deve ter sido, nos anos 1830, a partir de posições sociais e ofícios/profissões diferentes (Bruner, 1994).

New Salem Historic Site não é uma exceção à regra; ele faz parte de um numeroso conjunto de vilas e vilarejos reconstruídos pelo país, principalmente no Meio Oeste dos Estados Unidos da América. Eco (1986) traz uma boa explicação do gosto dos estadunidenses por reconstruções e reconstituições, bem como alguns dos melhores exemplos presentes na literatura.

No Brasil, as poucas reconstruções existentes seguem a linha de cidades cenográficas, e, infelizmente, são marcadas por notável ausência de interpretação patrimonial ou encenação histórica, o que reduz muito seu apelo turístico. A reconstrução da antiga Vila de São Vicente, no município de mesmo nome (Estado de São Paulo), é um bom exemplo disso. 


\section{O PACOTE DE ATRAÇÕES E OUTROS ELEMENTOS TURÍSTICOS E DE LAZER}

Em resumo, McKercher e Cros (2002, p. 112, tradução nossa ${ }^{7}$ ) definem o pacote de produtos (bundling) como: “[...] é uma opção mais realista e econômica disponível para muitas comunidades. [O pacote de produtos] é definida como a provisão de produtos e serviços separados como um pacote ou conjugação (Aaker, 1995; Brown, 1997)”.

De modo geral, o pacote de produtos consiste em um passaporte, cartão ou passe, vendido por uma firma privada, organização não governamental ou instituição pública que, mediante o pagamento de um valor, permite ao cliente o livre acesso a uma série de atrações turísticas de uma área determinada, durante um período de tempo pré-estabelecido. Isso permite ao cliente dois pontos, a saber:

a) a economia no preço dos ingressos e outros pagamentos, já que é de praxe o pacote de produtos dar acesso a uma série de atrações cujos ingressos, somados, resultam em um valor acima do preço do passaporte, cartão ou passe;

b) a divulgação da oferta turística do destino: é usual que o cliente receba um material que o informe acerca de tudo que está incluso no produto. Isso faz com que o turista fique mais bem informado sobre as atrações e outros elementos do destino.

Além de atrações, o pacote de produtos pode incluir livre acesso ou descontos em meios de transporte selecionados, bares e restaurantes, lojas etc.

Silberberg (1995), em influente e seminal artigo acerca do uso do pacote de produtos no mercado de turismo cultural, aponta seus três tipos principais, a saber:

a) entre atrações turístico-culturais do mesmo tipo: trata-se de algo intuitivo; por que não fazer um passe para os cinco museus do destino, por meio do qual o turista pode visitar todos, mas paga apenas por três ou quatro deles? Operacionalmente, há uma facilidade - os dirigentes dos museus trabalham no mesmo campo profissional, compartilham a mesma linguagem, e tendem a ter agendas próximas. Contudo, esse tipo de produto tende a ter uma demanda restrita;

b) entre atrações turístico-culturais de tipos diferentes: trata-se de um cartão, passe ou passaporte que combine, por exemplo, museus e centros culturais (para os períodos

\footnotetext{
${ }^{7}[\ldots]$ is a more realistic and cost-effective option available to many communities. It is defined as the provision of separate products and services to buyers as a package or bundle (Aaker, 1995; Brown, 1997).
} 
matutino e vespertino) com teatros e passeios fantasmagóricos (para o período noturno). Apesar de ampliar sua demanda, é um produto que se restringe, geralmente, a uma parcela também diminuta do mercado de turismo cultural;

c) entre atrações turístico-culturais e outros tipos de atrações, meios de transporte, alimentos e bebidas etc.: nos últimos anos, trata-se do tipo de pacote de produtos que mais se expandiu, por considerar - corretamente - que a maior parte do mercado de turismo cultural é formada por turistas com interesse secundário ou mesmo tangencial em cultura e patrimônio, como bem demonstram McKercher (2002) e McKercher e Cros $(2002,2003)^{8}$. Os casos mais bem-sucedidos de pacote de produtos são os desse tipo.

Um bom exemplo do primeiro tipo é o Norfolk Museums Pass, que permite ao comprador, por R $\$ 215,50$ anuais, o livre acesso a 10 museus, $10 \%$ de desconto em suas lojas e cafeterias, desconto em eventos especiais (ligados a um ou mais desses equipamentos culturais) e um informe eletrônico regular (Norfolk County Council, 2017). Apesar de primariamente voltado aos residentes do Condado de Norfolk (Inglaterra), o passe também é adquirido por turistas - majoritariamente domésticos -, que combinam a visita a Norwich com Great Yarmouth, onde se localizam seis desses museus ${ }^{9}$.

No segundo tipo, uma iniciativa considerada bem-sucedida é o Hoi An passport, na cidade de mesmo nome, classificada como Patrimônio Mundial da Humanidade, no Vietnã. Com o passaporte, o turista tem acesso a ampla variedade de museus, monumentos e prédios históricos, bem como informações sobre as atrações turístico-culturais da cidade. No caso específico de Hoi An, Brooks (2008, p. 353, tradução nossa ${ }^{10}$ ) defende que o produto é um sucesso turístico e patrimonial, pois:

A receita derivada da venda de ingressos é distribuída, de modo a prover apoio organizacional e promocional para atrações históricas na cidade, e para financiar a preservação [patrimonial] de prédios ou lugares históricos adicionais, de modo a

\footnotetext{
${ }^{8}$ McKercher (2002) e McKercher e Cros (2002, 2003) constroem uma valiosa tipologia dos turistas culturais, demonstrando que parte relevante do segmento de mercado é constituída por turistas com baixo interesse na cultura e no patrimônio do destino visitado.

${ }^{9}$ No caso da compra do passe por turistas, a informação verbal foi obtida com duas funcionárias do Norwich Castle: Museum \& Art Gallery, em 17 de abril de 2017.

${ }^{10}$ Income from ticket sales is distributed to provide organizational and promotional support for individual historic attractions within the town, and to fund the actual conservation of additional buildings or historic places, thus expanding the overall heritage and tourism resources of the town. A relatively minor proportion of the income is directed towards administration, which is the responsibility of the local authorities.
} 
expandir os recursos patrimoniais e turísticos da cidade. Uma parte relativamente pequena dessa receita é direcionada à administração, que está sob a responsabilidade das autoridades [públicas] locais.

Já o pacote de produtos entre atrações turístico-culturais e outras atrações, meios de transporte, bares e restaurantes e outros elementos é o tipo mais popular. No Reino Unido, um produto muito popular entre turistas é o York Pass, que dá acesso a cerca de 30 atrações turísticas pagas, descontos em lojas e serviços e abatimentos em passeios e meios de transporte selecionados. O produto segue a mesma lógica de passes em outros destinos turísticos importantes, a exemplo de Londres (London Pass) e Nova Iorque (New York Pass).

A organização pública English Heritage - que, conjuntamente com a Historic England, tem atuação similar ao Instituto do Patrimônio Histórico e Artístico Nacional, no Brasil comercializa um pacote de produtos voltado apenas para turistas internacionais, o Overseas Visitor Pass. Por meio dele, ao preço de R \$ 175,43 (nove dias) ou de R\$ 210,52 (16 dias), um turista adulto tem livre entrada em todas as atrações turístico-culturais pagas do English Heritage, que se distribuem por toda a Inglaterra, bem como a gratuidade ou abatimento em centenas de eventos e o recebimento de um guia turístico editado pela própria instituição (English Heritage, s/d).

\title{
4. O DESENVOLVIMENTO DE TRILHAS E ROTEIROS PATRIMONIAIS
}

Murta e Goodey (2002, p. 36-37) bem descrevem em que consistem as trilhas e roteiros turísticos:

\begin{abstract}
Uma trilha é uma rota, já existente ou planejada, que liga pontos de interesse em ambientes urbanos ou naturais. Por ser geralmente autoguiada, uma trilha deve ter algum tipo de sinalização ou interpretação ambiental para orientar o visitante e ajudá-lo a entender o que vê no caminho. A orientação é dada também por mapas e folhetos, contendo descrições e ilustrações dos principais marcos e características encontrados ao longo da trilha. [...] Como se prestam a caminhadas, as trilhas sinalizadas orientam e revelam ao visitante os principais marcos ambientais e culturais das localidades.
\end{abstract}

Os roteiros são percursos mais amplos e podem ser realizados através de qualquer meio de locomoção: bicicleta, cavalo, carro, barco e até mesmo a pé. Não importa a forma que tomem, sempre serão pontuados por atrações e serviços ao longo do caminho, entre os quais certamente figurarão trilhas para caminhadas.

É muito comum, em cidades nas quais o núcleo antigo concentra expressivo acervo de museus, monumentos, prédios históricos e conjuntos arquitetônicos patrimoniais, que o poder público local estabeleça uma ou mais trilhas turísticas, por meio das quais o turista consiga “rentabilizar" seu tempo, conhecendo o que a cidade tem de mais interessante e atrativo. 
A popularidade das trilhas faz com que a iniciativa privada também as desenvolva ou explore. A editora inglesa Metropublications ltd, que publica a linha Metro Guides - guias turísticos voltados a públicos-alvo bem definidos, mas sempre sobre a Grande Londres -, lançou com grande sucesso a série “As caminhadas escondidas de Londres” (London's Hidden Walks), já em seu terceiro volume.

De autoria de Stephen Millar, os três volumes trazem 37 sugestões de caminhadas. Em freguesias tradicionais, a exemplo de Westminster, as trilhas combinam atrações principais (flagship attractions) com logradouros e caminhos pouco frequentados pelos turistas, mas que revelam prédios e histórias interessantes da Grande Londres. Já em Brixton, freguesia estigmatizada socialmente, a trilha sugerida leva o turista para um moinho de vento (1816), o Little Ben (1905), parecido com o Big Ben, mas em escala reduzida, e locais ligados aos imigrantes afro caribenhos, chegados à área nos anos 1960 (Millar, 2014).

Em alguns casos, as trilhas podem ser montadas a partir de determinado tema ou tipo de objeto de interesse. A tematização pode tornar interessante e atrativo objetos e lugares aparentemente desprovidos de interesse turístico. Por meio do World War Two Heritage Project, o Condado de Essex, a leste e nordeste da Grande Londres, implantou uma série de trilhas circulares de um dia, em regiões rurais, a fim de aproveitar os remanescentes de mais de 3.000 construções feitas durante a Segunda Guerra Mundial, em resposta a uma possível invasão do país.

O conjunto de trilhas, cuja mais longa mede 7,6 quilômetros, passa por estruturas arquitetônicas deterioradas, abandonadas e redundantes - no mais das vezes, plataformas, casamatas e pequenos prédios de concreto armado já muito desgastado. A ligação com a Segunda Guerra Mundial faz com que elementos individualmente indecifráveis e desprovidos de interesse tornem-se, por meio da implantação de trilhas e de interpretação patrimonial, um produto turístico voltado a aficionados.

A Figura 1 retrata parte do panfleto da trilha Cudmore Grove, de 3,2 quilômetros, uma das implantadas pelo World War Two Heritage Project: 


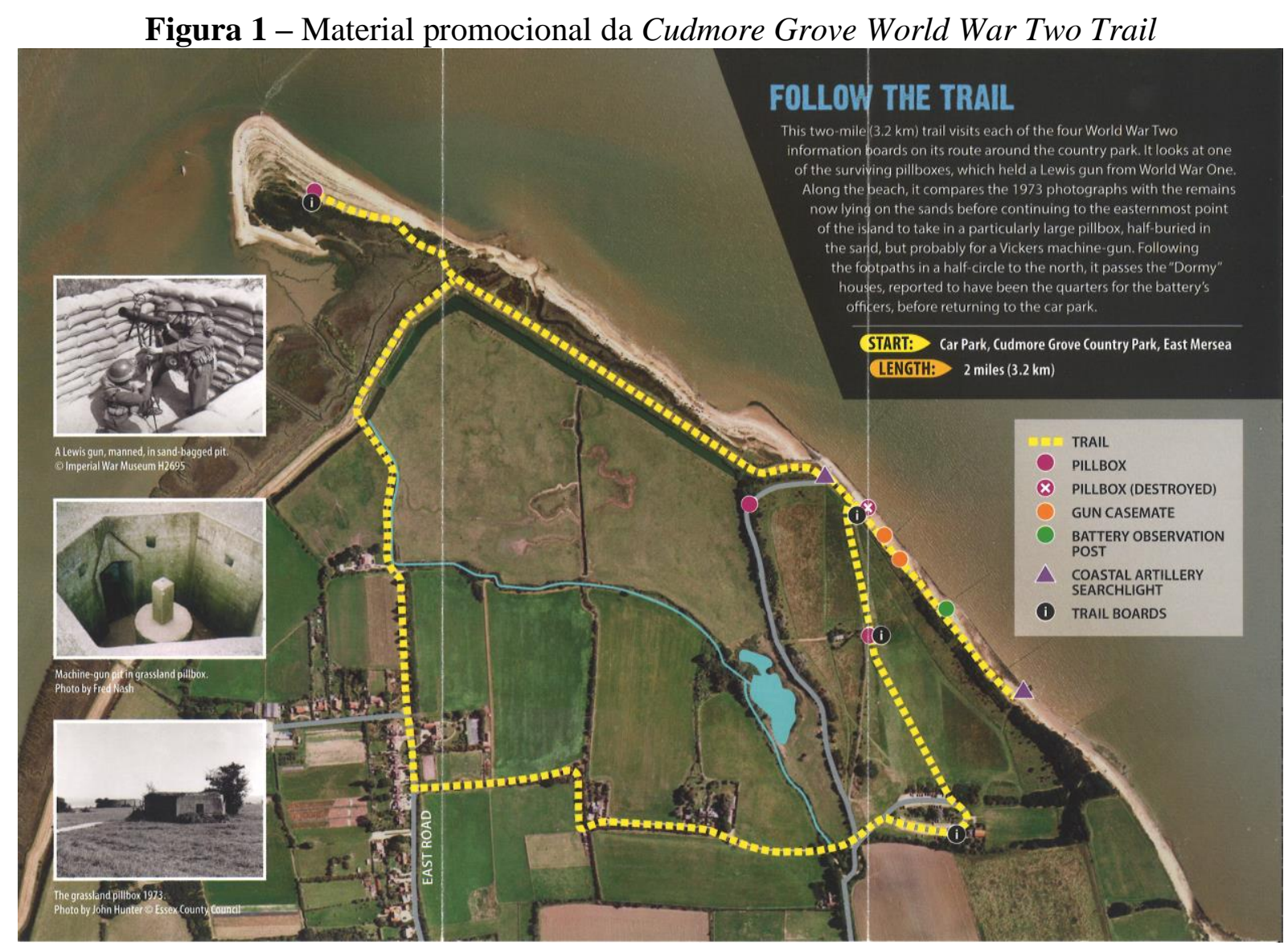

Fonte: Essex County Council, 201-?.

O panfleto reúne os pontos necessários para a promoção de uma trilha patrimonial, a saber: a) ele aponta a importância da trilha na história do país, ligando-a à Segunda Guerra Mundial; b) a foto aérea do panfleto complementa a sinalização de direcionamento; c) a interpretação patrimonial in loco é enriquecida com dados e informações presentes no folheto; e d) o folheto indica como se obter mais informações sobre o projeto.

Ao contrário de o que ocorre com grandes cidades e destinos turísticos importantes, muitos municípios e regiões não têm uma oferta capaz de atrair grande quantidade de turistas e visitantes, nem sequer dispõem de recursos para financiar grandes projetos. Sendo assim, cumpre investir em ações voltadas a públicos-alvo específicos, compostos, muitas vezes, por aficionados.

Dentro dessa lógica, muitos poderes públicos locais publicam folhetos muito elaborados - que, às vezes, assumem a forma de pequenos livretos - sobre o núcleo antigo da cidade ou distrito, com riqueza de detalhes. A Cidade de Wigan (Inglaterra) publicou, em 1998 e 2000, dois livretos com trilhas patrimoniais em seu núcleo antigo e no Distrito de Leigh, cujo nível de detalhamento chega à descrição dos antigos usos e proprietários de 
prédios históricos da cidade, mostrando sua trajetória particular (Wigan Metropolitan Borough Council, 1998; Wigan Council, 2000).

Outro produto muito encontrado na Inglaterra, mas ainda raro no Brasil, são as trilhas que combinam a área urbana com a zona rural; nestas, o caminho geralmente passa por prédios históricos e monumentos. Infelizmente, mesmo cidades com grande potencial para isso, a exemplo de Ouro Preto (Minas Gerais), Igarassu (Pernambuco) e Cachoeira e São Félix (Bahia), não costumam desenvolver muita coisa nesse sentido. No caso dessas quatro cidades, há poucas informações turísticas sobre o que existe para além do distrito-sede - na verdade, é difícil encontrar muita coisa sobre o que não se encontra no núcleo antigo -, e falta sinalização turística e de direcionamento para as atrações localizadas na zona rural.

É perceptível também a inexistência de trilhas delimitadas para caminhadas, por mais que - exceção à regra - Ouro Preto faça parte da Estrada Real (Caminho dos Diamantes, Caminho Novo e Caminho Velho).

\section{EVENTOS - DESTINOS TURÍSTICOS}

Os eventos e festivais concentram, em um curto período, uma série de atrações, atividades e espetáculos que podem funcionar como uma atração turística por si só, ou complementar a oferta turístico-cultural de um destino. No Brasil, a festa nacional por excelência é o Carnaval, que é notadamente forte em várias cidades patrimoniais - Ouro Preto (Minas Gerais), Olinda (Pernambuco), São Luiz do Paraitinga (São Paulo) etc.

Em muitos casos, os eventos concentram-se em períodos de baixa estação turística, de modo a se evitar uma alta taxa de vacância nos meios de hospedagem.

Em muitas cidades patrimoniais, é comum a realização de eventos anuais, de modo a complementar a oferta turístico-cultural, e combater a sazonalidade turística. Em York (Inglaterra), o Viking Festival ocorre na baixa estação turística, e chegou a sua $34^{\circ}$ edição, em 2019. Composto por simulações de batalhas, cursos, palestras e caminhadas, o ápice do festival ocorre com a encenação de uma batalha entre vikings e anglo-saxões, em 1043, e a queima de uma réplica em tamanho natural de um barco viking, em pleno Rio Ouse. Ele é organizado pelo York Archaeological Trust com o apoio do poder público local. Trata-se da espetacularização da história em um evento facilmente "consumível" para turistas e visitantes.

Em Olinda, o evento anual "Arte em Toda Parte," infelizmente interrompido por falta de recursos financeiros, promovia a abertura dos ateliês e oficinas de arte no sítio histórico, em parte do mês de dezembro. Conhecido reduto de artistas e artesãos, o evento permitia que 
os turistas e visitantes combinassem a visita aos monumentos e casario histórico com o espaço de trabalho de quem produz arte na cidade, bem como em apresentações culturais.

Cumpre destacar que os eventos podem estar ligados à cultura e patrimônio locais, a exemplo do Viking Festival, ou apenas terem um caráter cultural geral, como a Festa Literária Internacional de Paraty, que, em 2019 , chegou a sua $17^{\circ}$ edição.

Por fim, em alguns destinos turísticos, têm surgido um tipo curioso de evento. Em Llandrindod Wells, no País de Gales, organiza-se anualmente o Llandrindod Wells Victorian Festival, em agosto, quando, durante uma semana, a população local é convidada - e muitos aceitam - a se vestir à moda vitoriana (1837-1901) ou à moda eduardiana (1901-1910). As vitrines das lojas são embelezadas com motivos e decorações comuns no Século XIX, o que deixa a localidade, aparentemente, com ares do passado. Até o presente momento, esse tipo de evento ainda não foi feito no Brasil, de forma contínua (anual, por exemplo).

\section{CENTRO DE INTERPRETAÇÃO PATRIMONIAL}

O centro de interpretação patrimonial é um tipo de equipamento cultural similar ao museu; não por acaso, muitos turistas e visitantes consideram-nos como museus. Não é incomum alguns centros de interpretação patrimonial designarem-se como museus, mesmo tendo uma proposta muito característica daquele tipo de equipamento cultural.

Contudo, ao contrário do museu, que se centra em um acervo, o centro de interpretação patrimonial é formado em torno de um tema, personalidade, narrativa ou classe profissional. Em muitos casos, o centro é desprovido de acervo físico, ou ele é inteiramente composto por objetos banais, pouco valorizados individualmente. O importante é a construção de uma narrativa sobre o tema, período ou objeto de interesse do centro, de modo que os turistas e visitantes, mas principalmente os residentes locais, possam apreciar a história em exposição, interpretar o patrimônio cultural local, e mais bem compreender a importância e relação do local dentro da região, país ou mesmo Mundo.

Desse modo, a interpretação patrimonial é um ponto fulcral nesses centros, dado que o acervo é escasso ou mesmo inexistente. Um bom exemplo disso era a proposta do Museu da Língua Portuguesa, instalado em parte da Estação da Luz (São Paulo, SP). Contando com acervo reduzido, o museu - que, apesar do nome, era um centro de interpretação patrimonial desenvolveu uma série de exposições, mostras interativas e filmes que permitiam que o público envolvesse-se e interagisse com o elemento básico de toda e qualquer cultura - sua 
língua. Por exemplo, em um grande painel interativo, os visitantes, por meio do toque, podiam formar palavras, compreendendo melhor como se deu sua formação ${ }^{11}$.

Apesar de ainda raros no Brasil, os centros de interpretação patrimonial têm experimentado expressivo crescimento, desde os anos 1970, na América do Norte e na Europa Ocidental. Um tipo comum é o centro que retrata a história e os costumes de uma localidade, quase sempre a partir da construção do conceito de comunidade coesa e delimitada social, temporal e geograficamente; ou, como coloca Dicks (1999, p. 349, tradução nossa), o centro: "[...] tende a codificar a comunidade como um mundo fechado e homogêneo."

No Reino Unido, o tipo de centro de interpretação patrimonial representado pelo Rhondda Heritage Park tem como um de seus exemplos pioneiros o Wigan Heritage Centre (The Way We Were), que encerrou as atividades no final dos anos 2000. Apesar de Wigan ser um destino turístico pouco importante, mesmo do ponto de vista regional, Hewison (1987) e Urry (2002) - textos seminais e influentes nas áreas de patrimônio cultural e de turismo, respectivamente - trazem análises detalhadas do projeto de regeneração urbana do porto fluvial da cidade e do centro da cidade; no segundo caso, ambos chamam a atenção para o conceito radicalmente diferente do presente em museus convencionais.

Dicks (1999) traz um excelente estudo de caso sobre o Rhondda Heritage Park, instalado em uma antiga mina de carvão desativada (Lewis Merthyr Colliery) no sudeste do País de Gales. O centro preserva a estrutura física da mina, e informa sobre a atividade econômica que sustentava centenas de comunidades no País de Gales, até meados dos anos 1950; contudo, seu foco é na comunidade que se desenvolveu em torno da mina de carvão.

O Rhondda Heritage Park define a comunidade local como algo coeso e homogêneo, por meio de sua delimitação no tempo, no lugar e em estilos de vida particulares: "Eles ligam eventos históricos, condições [políticas, sociais e econômicas] e figuras humanas em uma identidade narrativa, que os [indivíduos] imagina compartilhando uma unidade comum (logo, uma comunidade)" (Dicks, 1999, p. 351, tradução nossa ${ }^{12}$ ).

A transformação de um grupo social delimitado por um espaço " $\mathrm{x}$ " e por um tempo " $y$ " transforma-o em uma comunidade no centro de interpretação patrimonial, tratada, muitas vezes, como uma totalidade independente e autônoma. A construção dessa comunidade como uma identidade cultural distinta passa por três estratégias textuais, a saber: a) a

\footnotetext{
${ }^{11}$ No momento da escrita, o Museu da Língua Portuguesa ainda não tinha sido reaberto ao público, devido a incêndio ocorrido em 21 de dezembro de 2015.

12 They knit historical events, conditions and human 'characters' into a narrative identity that imagines them sharing a common unity (hence community).
} 
territorialização (territorialization), que se refere ao lugar; b) a etnização (ethnicization), que se refere às particularidades dos habitantes; e c) a temporalização (temporalization), que marca a comunidade em determinado horizonte temporal.

No caso da territorialização, o Rhondda Heritage Park destaca que o lugar foi marcante para o desenvolvimento e caráter da comunidade, dado que tudo girava em torno da exploração do carvão mineral, e, mesmo a atividade já tendo sido encerrada, há mais de 20 anos, ela deixou marcas profundas nas pessoas e no lugar. Já a etnização refere-se à construção de uma identidade cultural comum e de um estilo de vida particular pelos habitantes da região, o que resultou em um povo especial e diferente (nós), em relação ao de outros lugares e regiões do Reino Unido (eles) (Dicks, 1999).

Por fim, a temporalização, no caso do Rhondda Heritage Park, é trabalhada por meio do tempo cronológico, dos anos 1880 a 1958, com o destaque para os principais acontecimentos e personagens envolvidos com a extração de carvão e questões trabalhistas correlatas, e de maneira subjetiva, na qual momentos do passado são apresentados como se ainda ocorressem, destacando que todas as personagens ligadas ao centro (mineiros e suas famílias, autoridades, empresários do carvão etc.) passaram por aquele momento (Dicks, 1999).

É importante destacar que o Rhondda Heritage Park mobiliza, ao mesmo tempo, um discurso antropológico e um discurso político - em alguns casos, há contradições entre eles. Em suma, temos o seguinte:

a) o discurso antropológico documenta uma comunidade anacrônica e diferente, que não é mais facilmente encontrada no Mundo Ocidental, e que funciona como repositório de valores desejáveis. Ela precisa ser preservada e rememorada, daí a importância do centro de interpretação patrimonial;

b) o discurso político utiliza a comunidade como padrão e referência para o futuro, recorrendo, no caso do Rhondda Heritage Park, a um discurso socialista e trabalhista - ação coletiva, solidariedade, ideais trabalhistas, formas de resistência ao capital (sindicalismo, greves, entre outros) etc. (Dicks, 1999).

Uma crítica comum feita aos centros é que eles acabam por produzir uma história que é, acima de tudo, "artefatual," sem conseguir mostrar aos visitantes a relação do tema ou objeto em questão com o contexto social, econômico, político e cultural mais amplo. A 
questão da construção do mito de uma comunidade unida e coesa, isenta de conflitos - no que consiste em uma mitificação e em uma mistificação -, também é um ponto muito criticado.

Outro tipo de centro de interpretação patrimonial é o centrado em uma figura histórica. Em Salta (Argentina), foi aberto, em 2017, o Museo Güemes que, como bom centro de interpretação patrimonial, conta com um acervo exíguo de objetos, nenhum dos quais relacionado diretamente a Martín Miguel de Güemes, um dos heróis da independência argentina e a grande figura histórica do norte do país.

Apesar de estar localizado em uma antiga casa do Século XVIII, o que é "exposto" no centro de interpretação patrimonial são basicamente painéis, sons e filmes que encenam momentos marcantes da vida de Güemes e de Salta, no início do Século XIX, retratando a importância do militar para a independência argentina. $\mathrm{O}$ centro mitifica Güemes; por toda a cidade de Salta, há cartazes que valorizam sua atuação, nas primeiras décadas do Século XIX, apontando-o como exemplo de virtude e coragem para as gerações atuais.

\section{EVENTOS - ATRAÇÃO TURÍSTICO-CULTURAL}

Muitas atrações turístico-culturais combinam sua edificação e acervo material com a realização de eventos, de forma a tornar sua oferta mais atrativa para turistas, visitantes e residentes locais. Segundo Janiskee (1996), os eventos especiais permitem combinar as qualidades do prédio histórico em si com novas oportunidades de lazer e recreação; isso é especialmente importante para que a mesma pessoa visite a atração mais de uma vez.

$\mathrm{Na}$ gestão desses eventos especiais, o autor aponta que eles passam pela realização de atividades nas casas (por exemplo, exposições), pela organização de passeios e visitas internas em uma ou mais propriedades e pela recepção aos frequentadores - estacionamento, alimentos e bebidas etc. Os eventos especiais são de três tipos principais, a saber:

a) festivais comunitários;

b) passeios por dentro das edificações, às vezes por meio de pacotes que cobrem três ou quatro casas históricas, além de igrejas e outras estruturas arquitetônicas;

c) representações de história viva (living history portrayals):

As representações de história viva constituem a terceira categoria principal de eventos que empregam casas históricas. A característica distintiva desse tipo de evento é o papel central de artistas fantasiados, que demonstram ou encenam realisticamente atividades ou eventos do passado. Já que indivíduos em trajes passados são comumente utilizados para embelezar passeios por casas históricas, essa diferença não é sempre óbvia. Normalmente, contudo, uma produção de história viva é reconhecível como um evento orientado à ação, que usa a casa histórica como 
cenário ou pano de fundo. Assim, ao invés de ser a atração principal, como ocorre no passeio, a casa histórica funciona principalmente como o local para apresentações. (Janiskee, 1996, p. 407, tradução nossa ${ }^{13}$ )

\section{CONSIDERAÇÕES FINAIS}

Uma grande capital cultural europeia, a exemplo de Londres ou Paris, pode gastar relativamente pouco em turismo, e, eventualmente, não ter um posicionamento claro no mercado de turismo. Já no caso de Bananal (Estado de São Paulo), sua consolidação como destino turístico de importância regional demanda um trabalho sério e de longo prazo, que precisa contar com recursos externos, dado que o município é relativamente pouco desenvolvido. A pura e simples existência de um conjunto arquitetônico excepcional, no distrito-sede, e de importantes fazendas de café do Século XIX, em sua zona rural, não garantem o sucesso turístico da cidade, por si sós. A criação, formatação, gestão e promoção de bens e experiências turístico-culturais são fundamentais para despertar o interesse da maior parte do segmento de turismo cultural.

Cumpre destacar três pontos. Primeiro, desde pelo menos os anos 1980, o crescimento do número de atrações turístico-culturais - museus, centros de interpretação patrimonial, parques temáticos com temas e atavios culturais etc. - tem sido, em sua maior parte, de responsabilidade da iniciativa privada e de organizações não governamentais, na América do Norte, Europa Ocidental e Sudeste Asiático. Esse fenômeno (ainda) não se verifica no Brasil, onde os supracitados equipamentos culturais são, em sua maioria, públicos. Isso acontece até mesmo em nossas principais cidades patrimoniais e destinos turísticos, a exemplo de Ouro Preto, Olinda, Rio de Janeiro e São Paulo.

Enquanto no exterior há o fenômeno do encerramento de atrações turístico-culturais, ocorre um desinteresse da iniciativa privada em abrir museus e centros de interpretação patrimonial pagos, mesmo em nossas principais cidades patrimoniais.

Segundo, mesmo tendo como objetos o antigo, o tradicional, a história e o patrimonial, avalia-se que as atrações turístico-culturais e destinos que dependem do turismo cultural precisam sempre apresentar algo "novo," para conseguirem competir em um mercado crescentemente competitivo. Esse "novo" pode ser a abertura ou ampliação de uma atração

\footnotetext{
${ }^{13}$ Living history portrayals comprise the third major category of events that employ historic houses. The distinguishing feature of this type of event is the central role of costumed entertainers who realistically demonstrate or reenact activities and events of the historic past. Since individuals in historical garb are commonly used to embellish house tours this difference is not always obvious. Normally, however, a living history production is recognizable as an action-oriented event that uses an historic house setting or backdrop. Thus, instead of being the main attraction, as it is in the house tour mode, the historic house functions primarily as a venue for entertaining performances.
} 
turístico-cultural, no caso de um destino turístico. Ele pode ser também a constante renovação da interpretação disponível ou a troca constante de exposições temporárias, baseadas em vasta reserva técnica ou na atração de acervos de forma temporária.

Por fim, a "importação" de modelos e tipos de atrações turístico-culturais, a exemplo dos centros de interpretação patrimonial, seria algo inovador para o mercado de turismo cultural no Brasil, mesmo que alguns desses modelos e tipos já estejam sendo implantados no exterior, desde pelo menos os anos 1980.

Infelizmente, a criação, formatação, gestão e promoção de bens e experiências turístico-culturais encontra-se em estado muito rudimentar no Brasil, o que é um dos fatores que dificulta o crescimento do turismo cultural no país.

\section{REFERÊNCIAS}

Abram, S. A. (1996). Reactions to tourism: a view from the deep green heart of France. In Boissevain, J. (Ed.). Coping with tourists: European reactions to mass tourism. Providence: Berghahn Books.

Apostolakis, A. (2003). The convergence process in heritage tourism. Annals of tourism research, 30(4), 795-812.

Boorstin, D. J. (1992). The image: a guide to pseudo-events in America. New York: Vintage Books.

Brooks, G. (2008). Exploiting the benefits of World Heritage listing: Evora, Portugal, and Hoi An, Vietnam. In: B. Hayllar, T. Griffin, \& D. Edwards. (Orgs.). City spaces - tourist places: urban tourism precincts. (pp. 341-355). Oxford: Butterworth-Heinemann.

Bruner, E. M. (1994). Abraham Lincoln as authentic reproduction: a critique of postmodernism. American anthropology, 96(2), 397-415.

Dicks, B. (1999). The view of our town from the hill: communities on display as local heritage. International journal of cultural studies, 2(3), 349-368.

Dodd, D., \& Hemel, A. (Eds.). (1999). Planning cultural tourism in Europe: a presentation of theories and cases. Amsterdam: Boekman Foundation, Ministry of Education, Culture and Science.

Eco, U. (1986). Travels in hyperreality. San Diego: Harcourt.

English Heritage. (s/d). Overseas visitor pass: visit over 100 historic attractions from $£ 31$. London: English Heritage.

Essex County Council. (201-?). Cudmore Grove World War Two Trail. Chelmsford: Essex County Council.

Hatherley, O. (2010). A guide to the new ruins of Great Britain. London: Verso.

Hatherley, O. (2012). A new kind of bleak: journeys through urban Britain. London: Verso. 
Herbert, D. T. (1996). Artistic and literary places in France as tourist attractions. Tourism management, 17(2), 77-85.

Hewison, R. (1987). The heritage industry: Britain in a climate of decline. London: Methuen.

Janiskee, R. L. (1996). Historic houses and special events. Annals of tourism research, 23(2), 398-414.

Köhler, A. F. (2009). Autenticidade: origens e bases da discussão em turismo. Revista turismo - visão e ação, 11(3), 282-303.

Köhler, A. F. (2011). Políticas públicas de regeneração urbana, preservação do patrimônio e lazer e turismo: padrões de intervenção pública e avaliação de resultados no Pátio de São Pedro, Recife, 1969-2008. 2011. 673f. Tese de Doutorado em Arquitetura e Urbanismo, Programa de Pós-Graduação em Arquitetura e Urbanismo, Universidade de São Paulo, São Paulo, SP, Brasil.

McKercher, B. (2002). Towards a classification of cultural tourists. International journal of tourism research, 4(1), 29-38.

McKercher, B., \& Cros, H. (2002). Cultural tourism: the partnership between tourism and cultural heritage management. Binghamton: Haworth Hospitality Press.

McKercher, B., \& Cros, H. (2003). Testing a cultural tourism typology. International journal of tourism research, 5(1), 45-58.

Millar, S. (2014). London's hidden walks 3. London: Metropublications.

Moore, R. (2014). The buildings that won the national lottery jackpot - the hits and misses. Recuperado de http://www.theguardian.com/artanddesign/2014/nov/02/national-lotteryfunding-buildings-won-jackpot-architecture-hits-and-misses

Moscardo, G., \& Pearce, P. L. (1999). Understanding ethnic tourists. Annals of tourism research, 26(2), 416-434.

Murta, S. M., \& Goodey, B. (2002). Intepretação do patrimônio para visitantes: um quadro conceitual. In S. M. Murta, \& C. Albano. (Orgs.). Interpretar o patrimônio: um exercício do olhar. Belo Horizonte: Ed. UFMG, Território Brasilis.

Norfolk County Council. (2017). It pays to have a Norfolk Museums Pass. Norwich: Norfolk County Council.

Plaza, B. (2000). Guggenheim's museum's effectiveness to attract tourism. Annals of tourism research, 27(4), 1055-1058.

Richards, G. (1996). Cultural tourism in Europe. Wallingford: CAB International.

Silberberg, T. (1995). Cultural tourism and business opportunities for museums and heritage sites. Tourism management, 16(5), 361-365.

Stanton, M. E. (1989). The Polynesian Cultural Center: a multi-ethnic model of seven Pacific cultures. In V. L. Smith. (Ed.). Hosts and guests: the anthropology of tourism. (2a. ed.). Philadelphia: University of Pennsylvania Press. 
Turner, L., \& Ash, J. (1976). The golden hordes: international tourism and the pleasure periphery. New York: St. Martin's Press.

Urry, J. (2002). The tourist gaze. (2nd. ed.). London: Sage.

Wigan Council. (2000). Leigh town trail: two guided walks in Leigh town centre. Wigan: Wigan Council.

Wigan Metropolitan Borough Council. (1998). Wigan town centre trail: comprising two guided walks in Wigan town centre. Wigan: Wigan Metropolitan Borough Council.

FORMATO PARA CITAÇÃO DESTE ARTIGO

KOHLER, A. F. (2020). Criação, formatação, gestão e promoção de bens e experiências

turístico-culturais. Revista de Turismo Contemporâneo, 8(2), 251-273.

https://doi.org/10.21680/2357-8211.2020v8n2ID19001 